九州大学学術情報リポジトリ

Kyushu University Institutional Repository

\title{
Age Determination in the Yellow Weasel, Mustela sibirica coreana
}

Miyagi, Kuniharu

Zoological Laboratory, Faculty of Agriculture, Kyushu University

Shiraishi, Satoshi

Zoological Laboratory, Faculty of Agriculture, Kyushu University

Uchida, Teruaki

Zoological Laboratory, Faculty of Agriculture, Kyushu University

https://doi.org/10.5109/23764

出版情報：九州大学大学院農学研究院紀要. 27 (3/4)，pp. 109-114，1983-02. Kyushu University バージョン：

権利関係 : 


\title{
Age Determination in the Yellow Weasel, Mustela sibirica coreana*
}

\author{
Kuniharu Miyagi ${ }^{\dagger}$, Satoshi Shiraishi and Teru Aki Uchida \\ Zoological Laboratory, Faculty of Agriculture, \\ Kyushu University 46-06, Fukuoka 812 \\ (Received August 5, 1982)
}

\begin{abstract}
The age of 116 males of the yellow weasel, Mustela sibirica cureana, was determined by the cementum-layer of the canine tooth, and the characters of the baculum. Six age classes (from the yearling to the five-year age class) were distinguished by the dental annuli. The one-year age class involved many individuals, and was followed by the two-year age class and then the yearling one in the number. On the other hand, the specimens over three-year age classes were rare. A survivorship curve based on the age composition indicated that $77 \%$ of the population might die within two years of life for some reason. The mean of the ecological longevity for this species was calculated at about 2.1 years. There was a significant difference in the baculum weight between the group below the two-year age class and that of the two-year age class and over. The shape of the baculum used in conjunction with the baculum weight provided a fairly reliable clue for aging the weasels. Thus, the individuals below the two-year age class were regarded as juveniles, and those of the two-year age class and over as adults.
\end{abstract}

\section{INTRODUCTION}

The age composition of mustelids has been mainly determined by counting the number of annual layers in dentine or cementum of the tooth (Casey and Webster, 1975), or in periosteal zone of the mandible (Shibata and Yamamoto, 1977). The characteristics (weight and shape) of the baculum also have been used for a crude distinction between juveniles and adults (Elder, 1951; Walton, 1968). The aim of this study was to make clear the age composition of the yellow weasel, Mustela sibirica coreana, by using a combined method based on the canine tooth and baculum.

\section{MATERIALS AND METHODS}

One hundred and sixteen male weasels were collected in Maebaru-Machi, Itoshima-Gun, Fukuoka Prefecture from 2 to 30 December 1977. The grind-

* Reprint request should be addressed to Prof. T. A. Uchida.

t Present address: College of General Education, Okinawa Kokusai University, Ginowan 901-22. 
staining was applied to the cementum-layer method. The canine tooth extracted from the mandible was longitudinally ground to a thickness of about 200 $\mu \mathrm{m}$ by hand using initially grind powder of 800 meshes with water, then at about $40 \mu \mathrm{m}$ by 3,000 meshes fine grind powder. The section was decalcified for 1520 minutes with $5 \%$ nitric acid, and neutralized for 15.20 minutes in 5 $\%$ sodium sulfate solution after being briefly washed in running water, then washed again for 5-10 minutes in running water. After staining with Böhmer's hematoxylin for 10-15 minutes, the dental annuli were counted at the root. Each baculum was oven dried for 24 hours at $50^{\circ} \mathrm{C}$ after being brushed clean and weighed.

\section{RESULTS AND DISCUSSION}

In Mustelidae, the first dark band in cementum of the canine tooth is formed during the first winter after birth (Casey and Webster, 1975; Yoneda,
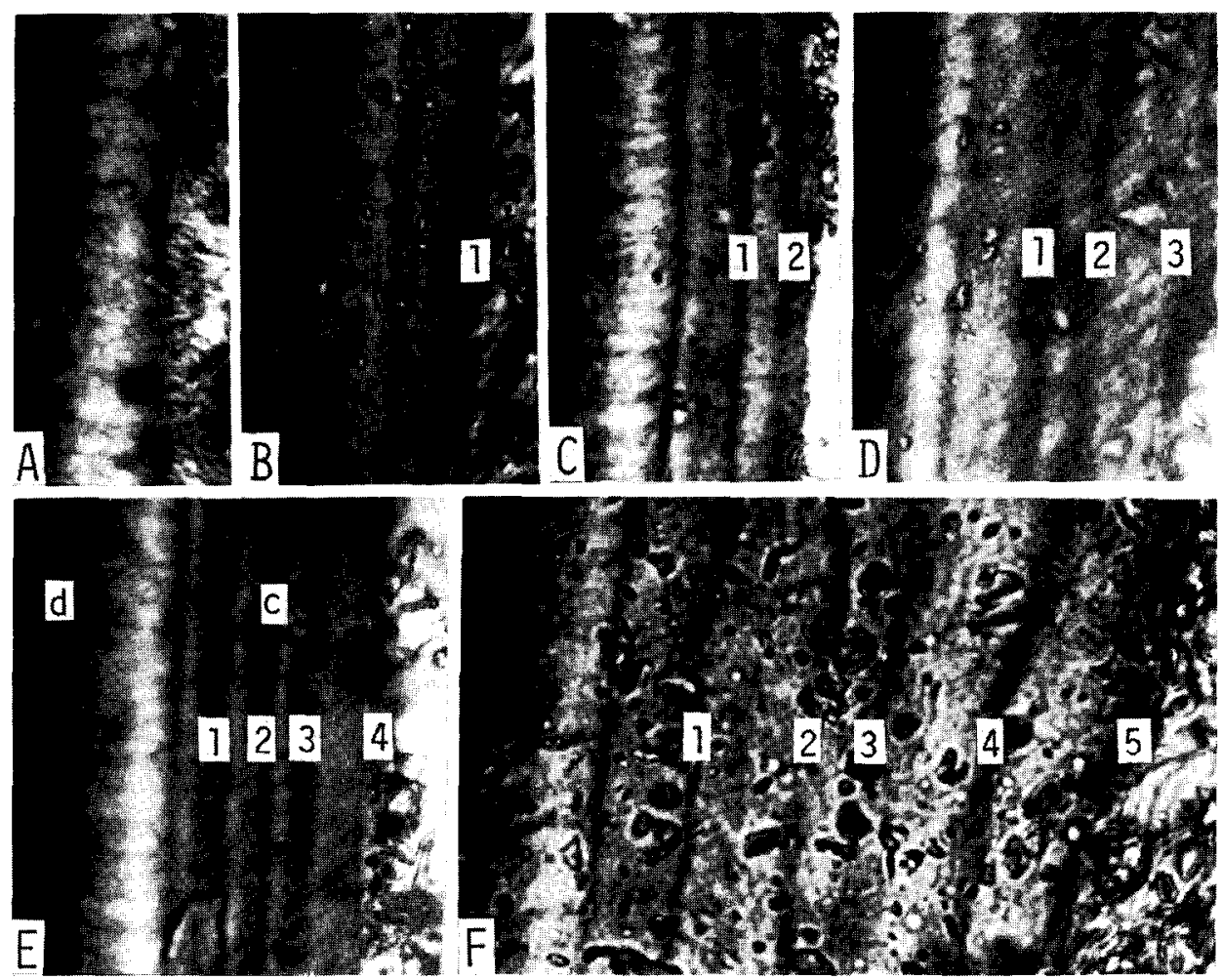

Fig. 1. Longitudinal sections of the canine roots of the yellow weasels. A, the yearling age class (no dark band in the cementum-layer) ; B, the one-year age class (one annulus); $\mathrm{C}$, the two-year age class (two annuli); $D$, the three-year age class (three annuli); E, the four-year age class (four annuli); F, the five-year age class (five annuli); c, cementum; d, dentine. $\times 520$. 
1977). The yellow weasel breeds generally from May to June. Therefore, a weasel having the canine teeth almost devoid of an annulus was determined to belong to the yearling age class (Fig. 1, A), the animals with one annulus and two annuli being determined to the one-year (Fig. 1, B) and two-year age class (Fig. 1, C), respectively. The three-year to five-year age classes were also decided in the same way (Fig. 1, D-F). Consequently, the age composition of the present sample was as follows: 6 individuals in the yearling, 83 in the one year, 21 in the two-year, 2 in the three-year, 3 in the four and 1 in the five-year age class. A survivorship curve based on the age composition indicated that $77 \%$ of the population might die within 2 years of life for some reason (Fig. 2). The mean of the ecological longevity for this species was calculated at about 2.1 years. Shibata and Yamamoto (1977) reported that about $65 \%$ of the Japanese weasel would die within a year after birth owing to some reason even in captivity. From these facts, it is assumed that the survivorship of the weasel in field may be more severe. This trend would be supported also by the fact that the marked and released weasels were rarely recaptured 2 years after the operation on Aoshima-Island, Matsu-ura-City, Nagasaki Prefecture (unpublished data).

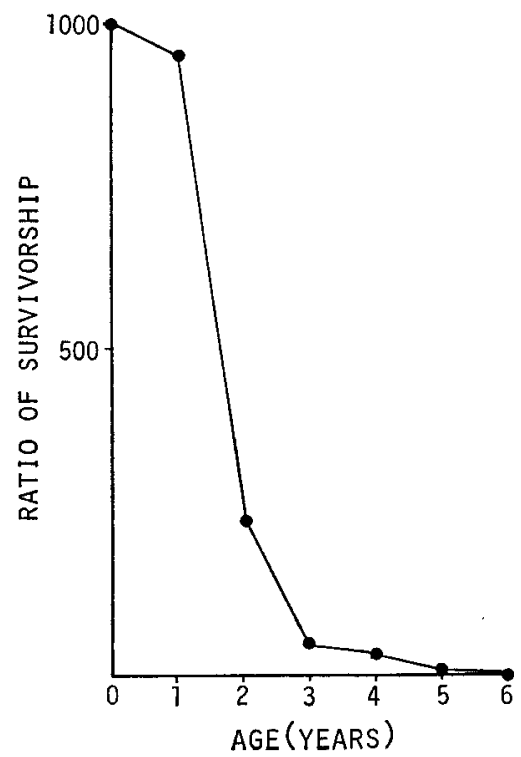

Fig. 2. A survivorship curve based on the age composition of the weasels.

Generally, in Mustelidae, juveniles (the yearling age class) can be distinguished from adults (the one-year age class and over) by the characteristics (weight and shape) of the baculum, but the age classes within the adults cannot be separated from one another (Friley, 1949; Wright, 1950; Elder, 1951; Mead, 1967; Walton, 1968; Ahnlund, 1976). In the yellow weasel, the baculum 
weight of individuals belonging to each age class which was correlated with the dental annuli was as follows: 0.112-0. $163 \mathrm{~g}$ (mean $0.134 \mathrm{~g}$ ) in the yearling, $0.112-0.232 \mathrm{~g}(0.154 \mathrm{~g})$ in the one-year, 0.225 -o. $358 \mathrm{~g}(0.299 \mathrm{~g})$ in the two-year, 0.267-o. $381 \mathrm{~g}(0.324 \mathrm{~g})$ in the three-year, 0.357-0. $445 \mathrm{~g}(0.402 \mathrm{~g})$ in the fouryear and $0.390 \mathrm{~g}$ in the five-year age class. There was no significant difference between the yearling and one-year age classes because both the ranges were overlapped, but a clear disparity existed between the group below the twoyear age class (i.e. the yearling and one-year ones) and the group of the two-year age class and over because of almost no overlapping between the two, although in both the two groups further yearly separation was impossible (Fig. 3).

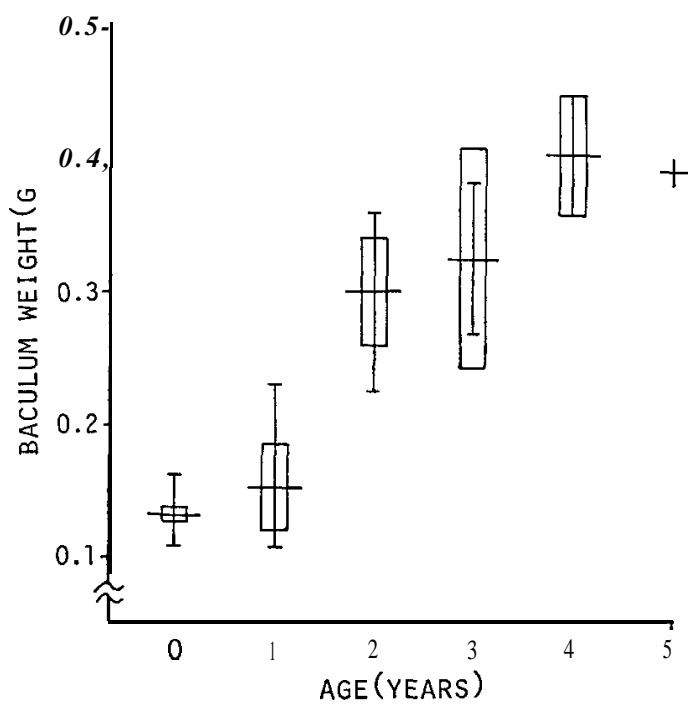

Fig. 3. The baculum weight in each age class in the weasels. The vertical, horizontal lines and block indicate the range, mean and standard deviation, respectively.

As to the shape of the baculum, the yearling age class had a simple sticklike baculum (Fig. 4, A) and the one-year age class possessed a slightly thick baculum with a little expanded knob at its base (Fig. 4, B), the two-year age class and over being characterized by a stout baculum with a remarkably expanded knobby base (Fig. 4, C-F). Therefore, the shape of the baculum used in conjunction with baculum weight provided a fairly reliable clue for aging the weasels. Wright (1950) demonstrated in the long-tailed weasel Mustela frenata that the onset of sexual activity coincided with a rapid growth of the baculum in the one-year age, due to stimulations by male sex hormones. In the yellow weasel, however, a rapid growth of the baculum was found in the two-year age class, and consequently this weasel seemed to reach sexual maturity at the age of two years if the coincidence mentioned adove in $M$. frenata is applicable to this species, too; the weasels below the two-year age 

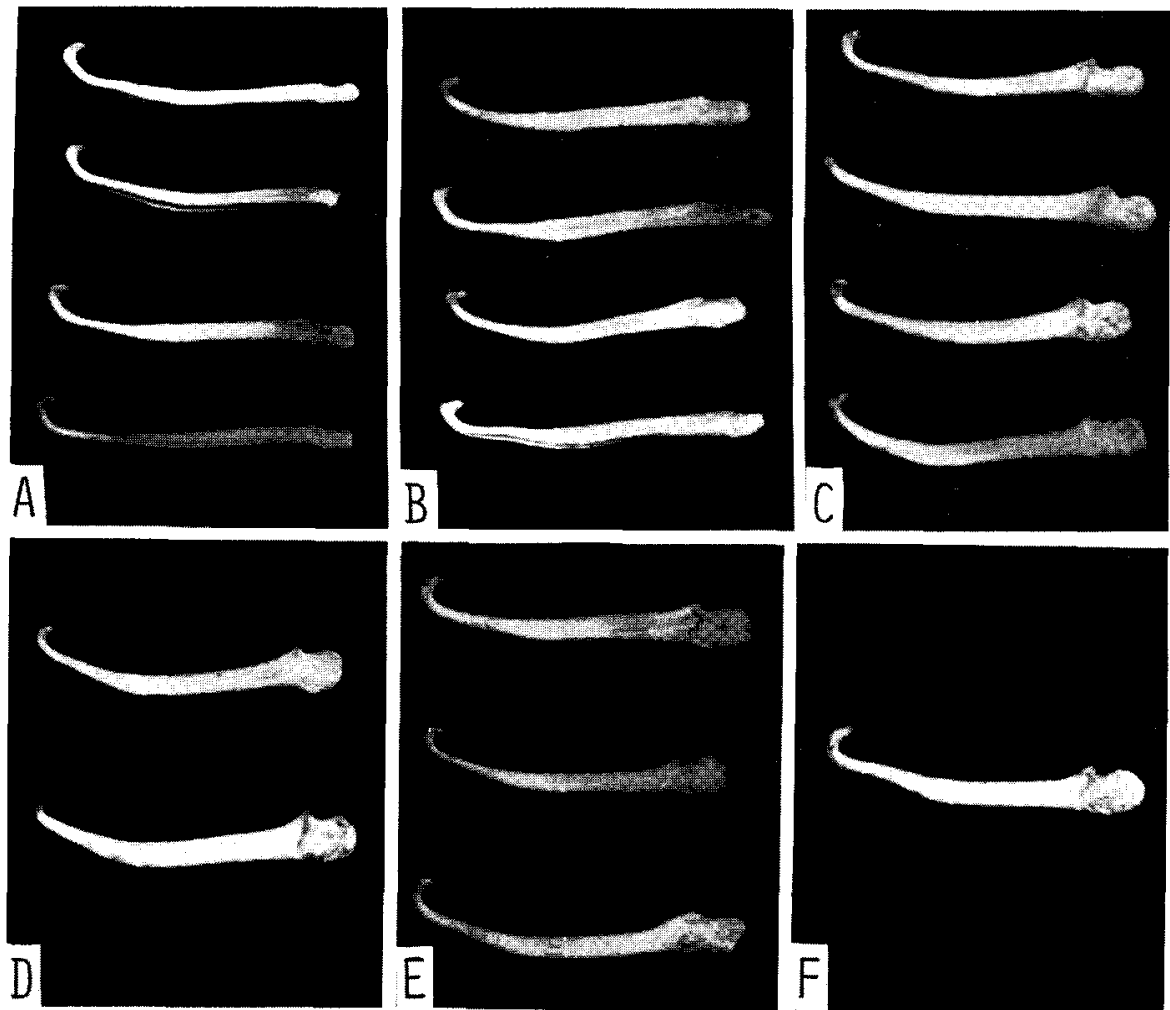

Fig. 4. A comparison of the baculum shape viewed from the left-hand side in each age class in the weasels. A, yearling age class; B, oneyear age class; C, two-year age class; D, three-year age class; E, fouryear age class; $F$, five-year age class. $\times 5 / 6$.

class were regarded as the juveniles, and the animals of the two-year age class and over as the adults.

As stated above, in the yellow weasel the six age classes were precisely determined by the cementum-layer method, in addition to a crude distinction between the juvenile and adult based on the characteristics of the baculum. In the case of a live animal, however, extraction of a canine tooth from the mandible is left to workers as a cruel treatment.

\section{ACKNOWLEDGEMENTS}

We are much indebted to Mr. Shigekichi Kebōshi in Maebaru-Machi, Itoshima-Gun, Fukuoka Prefecture for his help in collecting specimens, and to Professor E. W. Jameson, Jr. of the University of California for his comments on the manuscript. 


\section{REFERENCES}

Ahnlund, H. 1976 Age determination in the european badger, Meles meles L. Z. Säugetierk., 41: $119-125$

Casey, G. A. and W. A. Webster 1975 Age and sex determination of striped skunks (Mephitis mephitis) from Ontario, Manitoba, and Quebec. Can. J.Zool., 53: 223-226

Elder, W. H. 1951 The baculum as an age criterion in mink. J.Mamm., 32: 43-50

Friley, C. E., Jr. 1949 Age determination, by use of baculum, in the river otter, Lutrac. canadensis Schreber. J. Mamm., 30: 102-110

Mead, R. A. 1967 Age determination in the spotted skunk. J. Mamm,, 48: 606-616

Shibata, Y. and T. Yamamoto 1977 Age determination of the Japanese weasel from annual layers in the mandibular bone. Forest Pests, 26: 109-111 (in Japanese)

Walton, K. C. 1968 The baculum as an age indicator in the polecat Putorius putorius. J. Zool., Lond., 156: 533-536

Wright, P. L. 1950 Development of the baculum of the long-tailed weasel. Proc. Soc. Exptl. Biol. Med., 75:820-822

Yoneda, M. 1977 Age determination of carnivora. Honyurui Kagaku (Mammalian Science), (34) :66-73 (in Japanese) 